\title{
Insulin-like growth factor-1 restores dexamethasone-induced heart growth arrest in rats: the role of the ubiquitin pathway
}

\author{
Dionisios Chrysis ${ }^{1}$, Andrei S. Chagin ${ }^{2}$, Lars Sävendahl² \\ ${ }^{1}$ Department of Pediatrics, Division of Endocrinology, Medical School, University of Patras, Greece, ${ }^{2}$ Department of \\ Woman and Child Health, Endocrinology Unit, Karolinska Institute, Stockholm, Sweden
}

\begin{abstract}
OBJECTIVE: In skeletal muscle, glucocorticoids induce catabolism and proteolysis which is accomplished via the ubiquitin (Ub) proteolytic pathway. Cardiac muscle is a striated muscle which, compared to skeletal muscle, more abundantly expresses components of the Ub pathway, thus suggesting an important role for this pathway in heart physiology. The aim of our study was to explore the role of the Ub pathway in heart muscle physiology. DESIGN: We treated rats for three days with a pharmacologic dose of dexamethasone (DEXA) $0.5 \mathrm{mg} / 100 \mathrm{~g}$ body weight (BW). An attempt was also made to counteract the DEXA effect by co-treatment with insulinlike growth factor-1 (IGF-1; $0.35 \mathrm{mg} / 100 \mathrm{~g}$ BW). RESULTS: DEXA treatment caused a $7.8 \%$ decrease in heart weight compared to control $(\mathbf{p}<\mathbf{0 . 0 5})$ and also increased heart tissue levels of the ubiquitin-conjugating enzyme $\mathbf{E} 2$ and the $20 S$ proteasome protein. Myofibrillar proteins degraded by the ubiquitin pathway ( $\alpha$-actin, myoglobin, and troponin 1) were all decreased by DEXA, while ubiquitinated forms of $\alpha$-actin were increased. Co-treatment with IGF-1 completely prevented DEXA-induced decrease in heart weight, an effect which was accompanied by decreased heart tissue levels of several ubiquitinated proteins including $\alpha$-actin, the $20 \mathrm{~S}$ proteasome protein, E2-14kDa mRNA, and C-3 proteasome subunit mRNA, while the levels of non-ubiquinated $\alpha$-actin, myoglobin, and troponin 1 were all partially restored. CONCLUSION: These results demonstrate that DEXA activates the ubiquitin proteolytic pathway in the heart and that IGF-1 efficiently counteracts this effect. Our findings reveal a possible mechanism for the anti-proteolytic actions of IGF-1 and its cardioprotective role involving the Ub pathway.

Key Words: Apoptosis, Dexamethasone, Glucocorticoids, Heart, IGF-1, Ubiquitin, Ubiquitin pathway
\end{abstract}

\footnotetext{
Address for correspondence:

Dionisios Chrysis, M.D., Ph.D.

Department of Pediatrics, Division of Pediatric

Endocrinology, University Hospital, Rion, 26500 Greece

Tel.: +30 2610999 546, Fax: +30 2610994711

E-mail: dchrysis@upatras.gr

Received 22-01-10, Revised 10-07-10, Accepted 12-10-10
} 


\section{INTRODUCTION}

Glucocorticoids cause muscle atrophy in humans and animals by decreasing protein synthesis and increasing protein degradation. ${ }^{1}$ The ubiquitin (Ub) proteasome pathway is considered to be the principal pathway of proteolysis of myofibrillar proteins in skeletal muscle during glucocorticoid treatment..$^{2-5}$ This pathway carries out proteolysis of the ubiquitinated proteins targeted for degradation by sequential preparatory steps involving $\mathrm{Ub}, \mathrm{Ub}$-activating enzymes (E1), Ub-conjugating enzymes (E2), and Ub-ligases (E3). Briefly, Ub is activated by an E1 enzyme (requiring ATP), it is then transferred to one of the E2 enzymes, and finally, with the help of the E3 ligases, $\mathrm{Ub}$ is linked to the protein targeted for degradation. These steps are repeated and several Ub molecules are attached to the protein targeted for degradation. Finally, these steps are followed by proteolysis of the ubiquitinated protein by proteasomes (Figure 1). ${ }^{6}$ The Ub-pathway is important not only for the degradation of muscle proteins but also for the degradation of rate-limiting enzymes, proteins involved in the cell cycle (cyclins) and the removal of abnormal proteins. ${ }^{7}$ In heart muscle, mRNAs of different components of the Ub-pathway and proteasome activity are more abundant than in skeletal muscle ${ }^{8}$ and decline with age $^{9}$ suggesting a key role for heart muscle turnover. Studies showing that the E3-ligases are critical for maintenance of heart mass further support the concept that the Ub pathway plays an important role in heart physiology. ${ }^{10-12}$ The Ub pathway has also been implicated in various conditions affecting the heart such as diabetes, dilated cardiomyopathy, oxidative stress, and ischemia-reperfusion injury. ${ }^{8,13-15}$

Animal studies suggest that cardiac muscle is more resistant to the catabolic effects of glucocorticoids compared to skeletal muscle. ${ }^{16}$ Whereas the catabolic actions of glucocorticoids have been extensively studied in skeletal muscle, there are few reports directly addressing this issue in heart muscle. Glucocorticoid treatment has been reported to either increase or decrease, or else have no effect on protein degradation in heart muscle. ${ }^{17-20}$ Differences in the methodology of measuring protein degradation, glucocorticoid

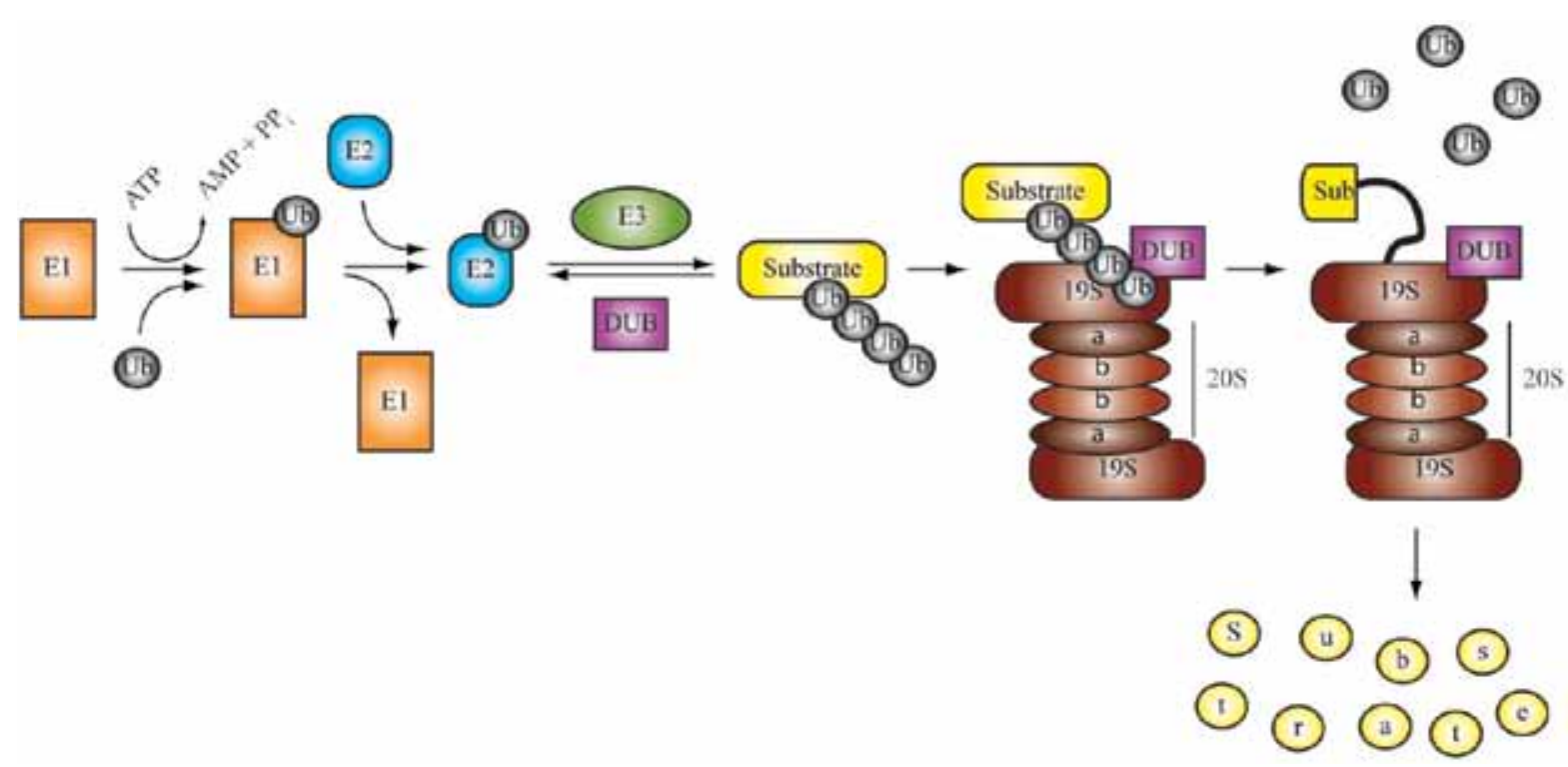

Figure 1. The ubiquitin proteasome pathway (Ub-pathway). ${ }^{6} \mathrm{Ub}$ is activated by an E1 enzyme requiring ATP. It is subsequently transferred to one of the E2 enzymes and finally, with the help of the E3 ligases, Ub is linked to the protein targeted for degradation. These steps are repeated and several Ub molecules are attached to the protein targeted for degradation. Polyubiquitinated proteins are recruited by the barrel-shaped 26S proteasome which is formed by the $20 \mathrm{~S}$ and $19 \mathrm{~S}$ particles containing different subunits. The $19 \mathrm{~S}$ particle possesses Ub-dependent proteolytic potential to remove Ub from the substrate for recycling, and ATPase activity to unfold the substrate protein which will be degraded into small peptides (yellow dots) by the $20 \mathrm{~S}$ core. The $20 \mathrm{~S}$ core is formed by different proteasome subunits. Deubiquitinating enzymes (DUB) counteract the activity of E3 and cleave Ub for recycling at the $26 \mathrm{~S}$ proteasome (with permission). 
dosing regimen, and animal age may account for this variability in reported data. In animal models of sepsis and burn injury, in which the endogenous production of glucocorticoids is increased, components of the Ub pathway have been reported not to be up-regulated. ${ }^{21,22}$

IGF-1 is an anabolic peptide which promotes growth not only by increasing cell proliferation and survival but also by increasing protein synthesis and decreasing protein breakdown. ${ }^{23,24}$ The anti-proteolytic actions of IGF-1 are considered to be mediated, at least partially, through the Ub-pathway. As an example, in models of catabolism, such as burn injury and glucocorticoid exposure, IGF-1 treatment has been shown to suppress Ub, E2 enzymes, E3 ligases, and subunits of the proteasomes. ${ }^{25-27}$ At the molecular level, these actions of IGF-1 are mainly mediated through the PI3-kinase/akt pathway which inhibits the transcription factor FOXO, an important stimulator of several E3-ligases. ${ }^{24,28}$ IGF-1 promotes heart growth and its administration increases cardiac mass and contractility. ${ }^{29-31}$ Furthermore, IGF-1 increases the synthesis of myocardial proteins in the rat heart like the heavy chain myosin, ${ }^{32}$ but it is not known whether it also exerts anti-catabolic actions by decreasing protein breakdown.

While, as mentioned above, there has been extensive examination in skeletal muscle of the catabolic actions of glucocorticoids, no studies currently exist that directly deal with this subject in heart muscle. The present study was designed to investigate the effects of pharmacologic doses of dexamethasone (DEXA) on heart muscle focusing on different components of the Ub-pathway. We also aimed to study if co-treatment with IGF-1 could prevent DEXA-induced catabolism and associated alterations of the Ub-pathway.

\section{MATERIAL AND METHODS}

\section{Reagents}

Digoxigenin (DIG)-11-UTP, DIG chemiluminescent detection reagents, DNA polymerase, RNA polymerases, positively charged nylon membranes, and a kit for immunoprecipitation were purchased from Roche Diagnostics Scandinavia AB (Bromma, Sweden). Recombinant IGF-1 was a gift from Pfizer. The puri- fication system for PCR products was obtained from Qiagen (Chatsworth, CA). TPIzol for RNA extraction was purchased from Life Technologies, Inc. (Grand Island, NY). PVDF membranes, protein molecular standards, and the ECL ${ }^{\text {plus }}$ chemiluminescent system for Western immunoblots were from Amersham Life Sci. (Arlington Heights, IL). Goat polyclonal antibodies against $\alpha$-actin, troponin 1 , and myoglobin were purchased from Santa Cruz Biotechnology (Santa Cruz, CA). The mouse monoclonal antibody FK1 which recognizes only polyubiquitinated proteins was purchased from Biomol (Enzo Life Sciences International Inc., Plymouth Meeting, PA). The E2-14kDa antibody was kindly offered by Dr Wing SS (McGill, Montreal, Quebec, Canada) and the antibody against the $\alpha$ subunit of 20S proteasome (clone MCP231) which recognizes subunits $\alpha 1, \alpha 2, \alpha 3, \alpha 5, \alpha 6$, and $\alpha 7$ was from Biomol (Enzo Life Sciences International Inc.). The MCP231 antibody was marketed by Affiniti Research Products Limited, a company which was later merged with Biomol, the company from which we bought the same antibody. Biomol was recently fully integrated into Enzo Life Sciences.

\section{Animals and experimental design}

Five-week-old male Sprague-Dawley rats (150g) were exposed to 12-h light, 12-h dark cycles, and fed ad libitum. After an adaptation period, 15 animals were randomly divided into 3 groups. One group received DEXA (DEXA group: $0.5 \mathrm{mg} / 100 \mathrm{~g}$ body weight (BW) per day, for 3 days) subcutaneously (SC). Another group received DEXA and IGF-1 in combination (DEXA/IGF-1 group: $0.5 \mathrm{mg} / 100 \mathrm{~g} \mathrm{BW} /$ day DEXA and $0.35 \mathrm{mg} / 100 \mathrm{~g}$ BW/day IGF-1, SC, divided into 2 daily doses, for 3 days), while a third group (control group) received a single daily injection of vehicle for 3 days.

At the end of the experimental period, the animals were sacrificed by intraperitoneal (IP) injection of phenobarbital and their hearts were excised, weighed, flash-frozen in liquid nitrogen, and stored at $-80^{\circ} \mathrm{C}$. The experimental protocol was approved by the local Ethics Committee at the Karolinska Institute.

\section{Northern hybridization analysis}

Northern hybridization analysis was performed as previously reported. ${ }^{14}$ Briefly, $15 \mu \mathrm{g}$ of total RNA 
extracted from heart (TRIzol, Life Technologies) was fractionated on a $1.2 \%$ agarose gel containing $2.2 \mathrm{M}$ formaldehyde, transferred overnight onto positively charged nylon membranes, fixed with UV crosslinking, and stained with methylene blue to ensure uniform loading and transferring. The membranes were hybridized overnight at $68^{\circ} \mathrm{C}$ in hybridization buffer, washed, and then subjected to chemiluminescent detection. Chemiluminescent signals were quantified densitometrically. Northern hybridization analysis was performed for the Ub, E2-14kDa enzyme, and C-3 proteasome subunit mRNAs by using the corresponding riboprobes as previously reported..$^{26,27}$

\section{Western immunoblotting and immunoprecipitation}

Total protein was extracted from the hearts with the modified RIPA buffer ${ }^{26}$ containing a protease inhibiting cocktail with phenymethylsulfonyl fluoride (Roche Diagnostics Scandinavia AB). Protein concentrations were measured via the Bradford method (BioRad, Hercules, CA). Equal amounts of protein were fractionated by $12 \%$ (or $8 \%$ for Ub) SDS-PAGE under reducing conditions. Resolved proteins were electrophoretically transferred to PVDF membranes and blocked overnight at $4^{\circ} \mathrm{C}$ in TBS-T (TBS, $10 \mathrm{mM}$ Tris and $150 \mathrm{mM} \mathrm{NaCl}, \mathrm{pH} 7.5$ with $0.1 \%$ Tween) containing $5 \%$ skim milk. Membranes were then incubated with primary antibodies (Ub: 1:750, $\alpha$-actin 1:2500, troponin 1 1:2000, myoglobin 1:2500, E2-14kDa 1:3000, 20 S proteasome 1:3000) in TBS-T containing $0.5 \%$ milk (E2-14kDa in TBS-T containing BSA) at room temperature for $1 \mathrm{~h}$, washed in TBS-T several times, and incubated with horseradish peroxidaseconjugated anti-rabbit immunoglobulin (Transduction Laboratories, San Diego, CA) at 1:10,000 dilution or anti-goat (Santa Cruz Biotechnology Inc, Santa Cruz, CA) at 1:3000 dilution. The antigen-antibody complexes were then detected by chemiluminescence. After development of films, blots were stained with Coomassie blue to ensure equal loading of total protein. In addition, in order to evaluate further the equal loading of total proteins, some blots were re-incubated with an antibody for the housekeeping protein GADPH (Santa Cruz Biotechnology Inc.).

Immunoprecipitation was carried out according to the manufacturer's protocol (Roche Diagnostics Scandinavia AB). Five hundred micrograms of total heart protein were precleaned with protein $\mathrm{G}$-agarose $\left(50 \mu \mathrm{L}\right.$ agarose for $2 \mathrm{~h}$ in rotor at $4^{\circ} \mathrm{C}$, and then another $50 \mu \mathrm{L}$ of agarose overnight). Beads were pelleted by gravity sedimentation and supernatants were removed. In each sample, $1 \mu \mathrm{g}$ of a goat polyclonal antibody against $\alpha$-actin was added and incubated for $1 \mathrm{~h}$ at $4^{\circ} \mathrm{C}$, then $50 \mu \mathrm{L}$ of protein- $\mathrm{G}$ suspension was added and incubated overnight at $4^{\circ} \mathrm{C}$. Complexes were collected by gravity sedimentation, washed twice for $20 \mathrm{~min}$ at $4^{\circ} \mathrm{C}$ on a rock platform with a buffer containing 50mM Tris-HCL, pH 7.5, 150mM NaCL, $0.1 \%$ Nonidet P40, $0.5 \%$ sodium deoxycholate and protease inhibitors, and another 2 times in washing buffer containing $50 \mathrm{mM}$ Tris-HCL, pH 7.5, $500 \mathrm{mM}$ NaCL, $0.1 \%$ Nonidet P40, $0.05 \%$ sodium deoxycholate, and then once in a buffer containing $10 \mathrm{mM}$ TrisHCL, $\mathrm{pH} 7.5,0.1 \%$ Nonidet $\mathrm{P} 40$ and $0.5 \%$ sodium deoxycholate. Immunoprecipitated proteins were dissolved in loading buffer and denatured by heating at $100^{\circ} \mathrm{C}$. An aliquot of immunoprecipitated proteins was analyzed by SDS-polyacrilamide electrophoresis and immunoblotted with an antibody against $\mathrm{Ub}$ (UG9510, Biomol, Enzo Life Sciences International Inc.). Normal goat serum instead of heart protein was used as a negative control during immunoprecipitation.

\section{Statistics}

All values are presented as median and range. Because of the small number of animals in each group, non-parametric one-way analysis of variance (ANOVA) was applied (Kruskal-Wallis test). Levels of significance were analyzed with Dunn's comparison post test and $p$ values $<0.05$ were considered significant. The statistical software program GraphPad Prism, version 5.02, was used.

\section{RESULTS}

\section{Body weight}

Rats treated for 3 days with DEXA alone lost weight by $12.2 \%$ (range $10.6-13.3 \%$ ) in contrast to control rats that gained weight by $16.2 \%$ (range 14.7$18 \%$ ) compared to their initial body weight (Table 1). Rats treated with the combination of IGF-1 and DEXA also lost weight ( $\mathrm{p}<0.5$ vs. control) but to a lesser degree than rats treated with DEXA alone (6.3\% (range $4.7-7.8 \%$ ) vs. $12.2 \%$ (range 10.6-13.3\%) weight loss; $p<0.015$ vs. DEXA). 
Table 1. Data obtained in animals treated with either dexamethasone (DEXA) or the combination of DEXA with insulin like growth factor-1 (DEXA/IGF-1) and in controls. Median values (range)

\begin{tabular}{lccc}
\hline & Controls & DEXA & DEXA/IGF-1 \\
\hline Initial BW $(\mathrm{g})$ & $167.5(161-168)$ & $168.0(165-175)$ & $167.5(163-170)$ \\
Final BW $(\mathrm{g})$ & $192.2(190-195.2)$ & $146.9(143.5-154.8)^{\mathrm{a}}$ & $156.7(155.4-157.2)^{\mathrm{c}, \mathrm{d}}$ \\
Change in BW (\% of base line) & $+16.2(14.7-18.0)$ & $-12.2(10.6-13.3)$ & $-6.3(4.7-7.8)^{\mathrm{b}}$ \\
Heart weight $(\mathrm{g})$ & $0.77(0.73-0.82$ & $0.71(0.69-0.73)^{\mathrm{c}}$ & $0.81(0.76-0.84)^{\mathrm{b}}$ \\
Heart weight $(\%$ of BW) & $0.40(0.39-0.42)$ & $0.48(0.47-0.49)^{\mathrm{c}}$ & $0.52(0.49-0.54)^{\mathrm{a}}$ \\
Change in heart weight $(\%$ of control) & & $-7.8 \pm 1.2$ & $+5.2 \pm 0.9^{\mathrm{b}}$ \\
\hline
\end{tabular}

${ }^{\mathrm{a}} \mathrm{P}<0.01$ vs. control, ${ }^{\mathrm{b}} \mathrm{P}<0.01$ vs. DEXA, ${ }^{\mathrm{c}} \mathrm{P}<0.05$ vs. control, ${ }^{\mathrm{d}} \mathrm{P}<0.05$ vs. DEXA, BW: body weight.

\section{Heart weight}

Following 3 days treatment with DEXA, heart weight was significantly lower when compared to vehicle treated control rats [0.71g (range $0.69-0.73$ ) vs. $0.77 \mathrm{~g}$ (range 0.73-0.82g); $\mathrm{p}<0.05]$. Co-administration of IGF-1 completely prevented DEXA-induced reduction in cardiac weight [0.81g (range 0.76-0.84g) heart weight in DEXA/IGF-1 vs. 0.71g (range 0.69-0.73g) in DEXA only; $\mathrm{p}<0.01]$. Moreover, heart weight in DEXA/IGF-1 rats showed a tendency to exceed that in control animals (Table 1).

\section{Ubiquitin (Ub) $m R N A$ and protein levels in heart}

DEXA treatment caused a small but significant decrease of the 2.8 and $1.2 \mathrm{~Kb}$ Ub transcripts $(68 \%$ of control, range $60-76 \%$; average of both transcripts; $\mathrm{p}<0.01$ ), an effect which could not be prevented by the co-administration of IGF-1 and DEXA (74\% of control; range 68-82\%). In contrast to mRNA levels, DEXA caused a significant increase in the total amount of ubiquitinated proteins above $60 \mathrm{kDa}(207 \%$ of control level; range 190-230\%; $\mathrm{p}<0.01$ ), an effect which was prevented by co-treating the animals with IGF-1 and DEXA (125\% of control; range $95-140 \%$; $\mathrm{p}<0.05$ vs. DEXA only; Figure 2A). These protein data were confirmed using a second anti-Ub antibody (UG9510, Biomol, Enzo Life Sciences International Inc.) that recognizes Ub-conjugated proteins.

\section{Ub-conjugating enzyme E2 in heart}

In contrast to Ub mRNA levels, DEXA treatment increased both the 1.8 and $1.2 \mathrm{~Kb}$ transcripts of the E2-14kDa enzyme (218\% of control; range $187-270 \%$; average of both transcripts; $p<0.01$ vs. control), an effect which was significantly prevented when animals were co-treated with IGF-1 and DEXA (142\% of control; range $123-157 \%$; $p<0.05$ vs. DEXA only, $p>0.05$ vs. control). When measuring E2-14kDa protein levels it was found that neither DEXA nor DEXA/IGF-1 treatment had any significant effect.

\section{Heart proteasome expression}

The mRNA level for the proteasome subunit C-3 was unaffected by DEXA treatment (90, range 80 $98 \%$ of control, $p>0.05)$, whereas IGF-1 significantly suppressed it (45\% of control, range 39-51\%, p $<0.05$ vs. DEXA). Western immunoblots with the $20 \mathrm{~S}$ antibody (recognizing $\alpha$-subunits $1,2,3,5,6$, and 7) revealed a significant increase in proteasome protein level by DEXA (140\% of control; range $134-160 \%$, $\mathrm{p}<0.05 \mathrm{vs}$. control), whereas the combined treatment with DEXA and IGF-1 completely prevented this increase (84\% of control; range 68.3-107.9\%, p $<0.01$ vs. DEXA only; Figure 2B).

\section{Heart expression of a-actin, myoglobin, and troponin 1}

DEXA treatment markedly reduced the $\alpha$-actin protein level (57\% of control; range 50-63\%, p <0.01), whereas IGF-1 partially restored it (78\% of control; range $65-93 \%, \mathrm{p}<0.05$ vs. control, and $\mathrm{p}>0.05$ vs. DEXA), (Figure 3A). The myoglobin protein level was decreased by DEXA (48\% of control; range 38$58 \%, \mathrm{p}<0.01)$, whereas co-administration of DEXA and IGF-1 partially restored it (78\% of control; range $68-81 \%, p<0.05$ vs. control group, and $\mathrm{p}>0.05$ vs. DEXA), (Figure 3B). Also the troponin 1 level was decreased by DEXA administration (47\% of control; range 35-59\%; $\mathrm{p}<0.01$ ), whereas IGF-1 and DEXA 


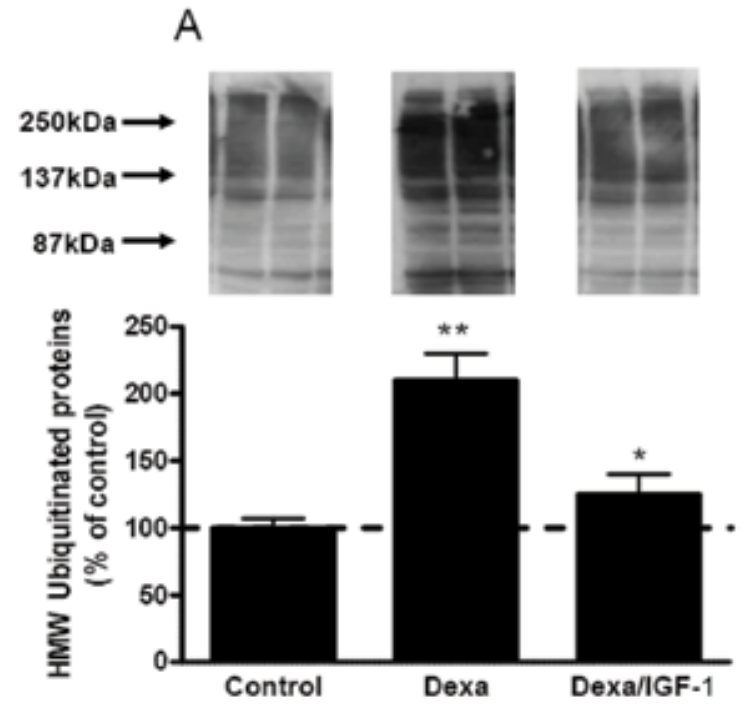

B

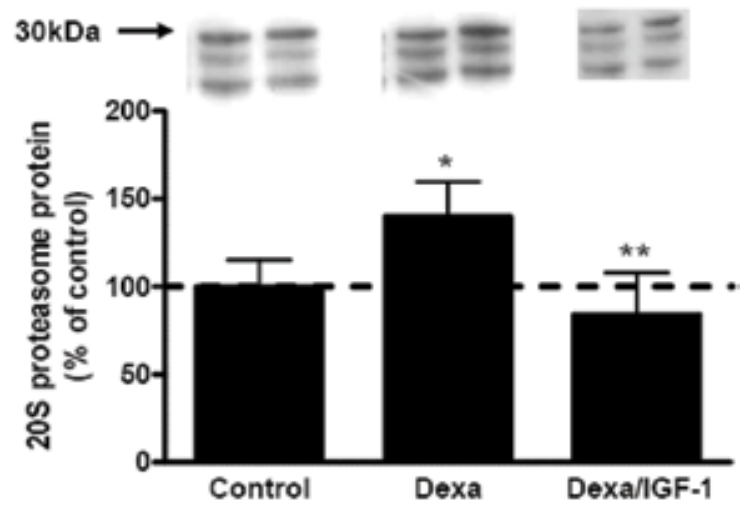

Figure 2. A: The effects of DEXA and IGF-1 on ubiquitinated proteins as assessed by western immunoblotting. Bands above $60 \mathrm{kDa}$ were quantified. Total ubiquitinated proteins were increased by DEXA compared to the control group $(* * p<0.01)$, while co-administration of IGF-1 reduced them significantly ( ${ }^{*} \mathrm{p}<0.05$ vs. DEXA). B: The effect of DEXA and IGF-1 on $\alpha$ proteasome subunits $1,2,3,5,6$, and 7 was assessed by western immunoblotting. DEXA increased the protein levels of proteasome subunits significantly ( ${ }^{*} \mathrm{p}<0.05$ vs. control, and $* * \mathrm{p}<0.01$ vs. DEXA/IGF-1) and the addition of IGF-1 restored them to control levels.

in combination partially restored troponin 1 (76\% of control, range $66-80 \%$; $p<0.05$ vs. control group, and $\mathrm{p}>0.05$ vs. DEXA) (Figure 3C).

\section{Ubiquitinated forms of a-actin in heart}

To investigate whether the decrease in $\alpha$-actin in heart was a result of increased activation of the Ubpathway, we immunoprecipitated $\alpha$-actin and then
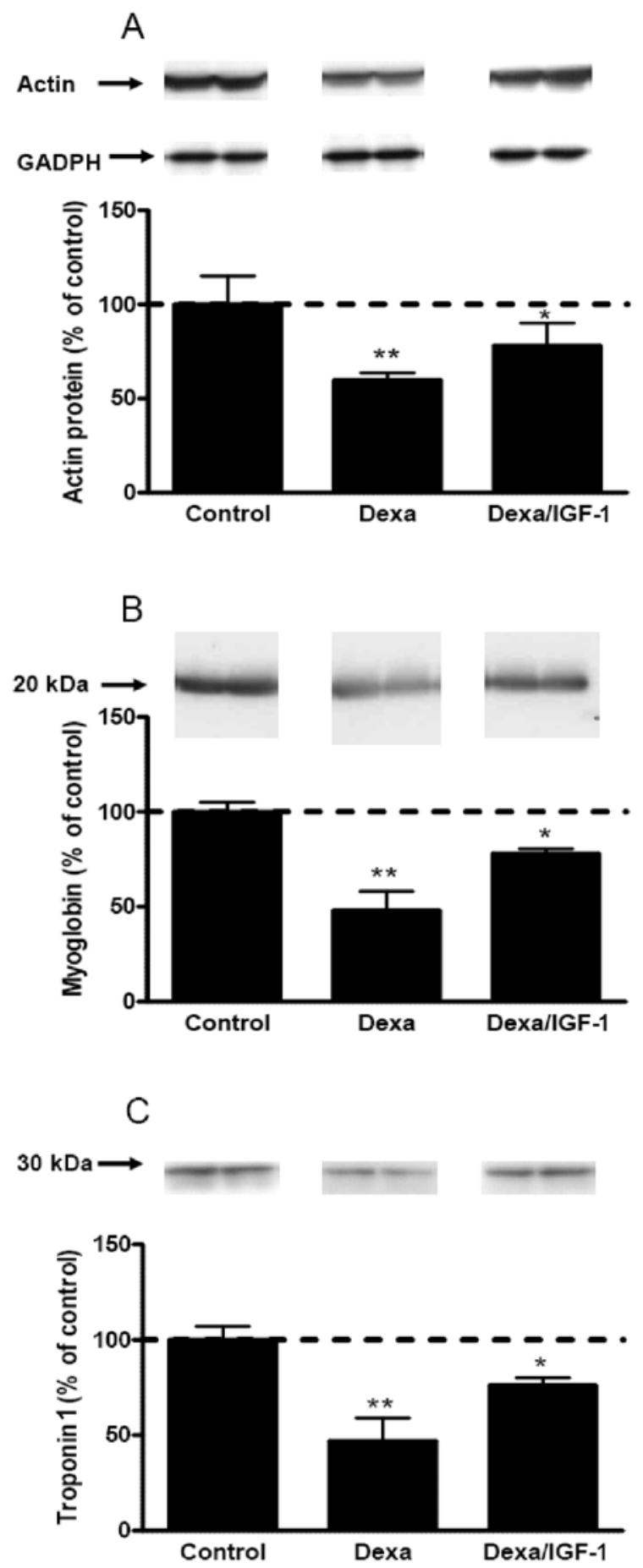

Figure 3. The effects of DEXA and DEXA/IGF-1 on myfibrillar proteins as assessed by western immunoblotting. A: DEXA caused a significant decrease in $\alpha$-actin expression $(* * p<0.01$ vs. control) and IGF-1 partially restored it ( ${ }^{*} \mathrm{p}<0.05$ vs. control). B: Myoglobin was decreased by DEXA $(* * p<0.01)$ and the addition of IGF-1 partially restored it ( ${ }^{*} \mathrm{p}<0.05 \mathrm{vs}$. control). C: Troponin 1 was also decreased by DEXA (**p $<0.01$ vs. control) and the addition of IGF-1 partially restored it $\left({ }^{*} \mathrm{p}<0.05\right.$ vs. control). 
performed immunoblotting for Ub. These experiments revealed that DEXA caused a several-fold increase in ubiquitinated forms of $\alpha$-actin (865\% of control; range $790-988 \%, \mathrm{p}<0.001)$, and the combined treatment with DEXA and IGF-1 partially prevented this increase (357\% of control; range 303-394\%, p<0.01 vs. DEXA alone), (Figure 4). Ubiquitinated forms of $\alpha$-actin were above $60 \mathrm{kDa}$ with a major band at $70 \mathrm{kDa}$. Immunoprecipitation with normal goat serum instead of heart protein was used as a negative control and gave no signal in the area of the ubiquitinated forms of $\alpha$-actin (data not shown).

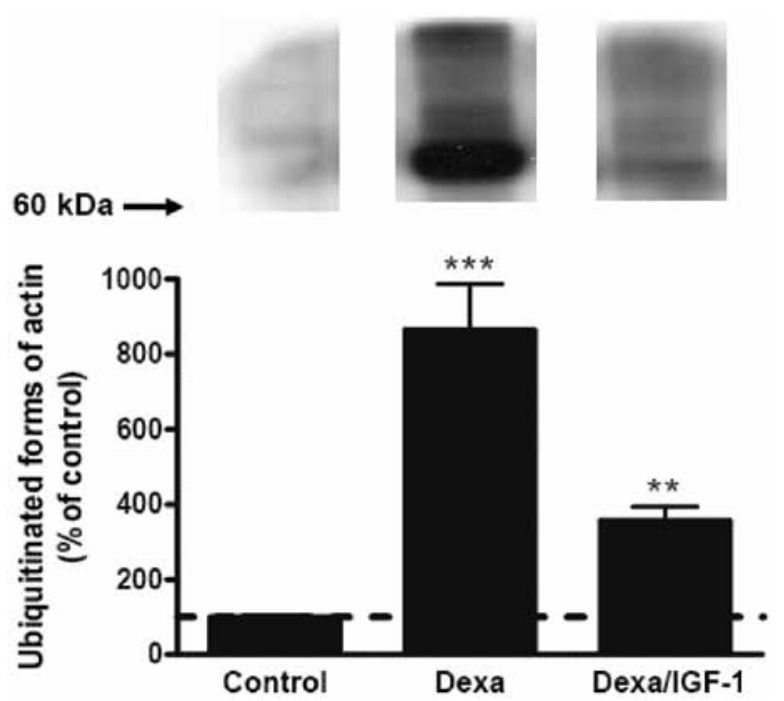

Figure 4. The effect of DEXA and IGF-1 on ubiquitinated $\alpha$-actin. Heart lysate from control, DEXA, and DEXA/IGF1 treated animals was subjected to immunoprecipitation for $\alpha$-actin followed by western immunoblotting for ubiquitin. DEXA treatment increased significantly ubiquitinated forms of $\alpha$-actin $(* * * p<0.001$ vs. control) with a major band above $60 \mathrm{kDa}$. Co-administration of IGF-1 to DEXA treated rats significantly reduced the ubiquitination of $\alpha$-actin $(* * p<0.01$ vs. DEXA alone).

\section{DISCUSSION}

We here report that pharmacological doses of DEXA inhibit heart growth in rats, an effect associated with decreased levels of the myofibrillar proteins $\alpha$-actin, myglobin, and troponin 1 and increased levels of the 20S proteasome and ubiquitinated proteins. Co-administration of DEXA and IGF-1 restored heart weight and the up-regulated components of the
Ub-pathway. Our results clearly show that DEXA activates different components of the Ub-pathway in heart muscle and that IGF-1 counteracts these effects.

Cardiac muscle has been considered more resistant to the catabolic actions of glucocorticoids compared to skeletal muscle. ${ }^{8,33}$ We herein provide evidence that the Ub-pathway is up-regulated in heart muscle after DEXA administration. We examined three different steps in the Ub-pathway: Ub, ubiquitin conjugating enzyme (E2-14kDa), and proteasomes. Our results show that all these components are affected by DEXA treatment, mainly and most significantly at the protein level. The accumulation of ubiquitinated proteins is a strong indication that protein ubiquitination is accelerated in heart after DEXA treatment suggesting increased proteolysis. If the Ub-pathway is activated, the myofibrillar proteins $\alpha$-actin, myoglobin, and troponin 1, reported to be degraded by the Ub-pathway, ${ }^{34-37}$ would be decreased after DEXA treatment. Indeed, we found that all these proteins decreased post DEXA and partially restored by the addition of IGF-1. Finally, immunoprecipitation experiments directly confirmed that the decrease in $\alpha$-actin after DEXA treatment was accompanied by a significant increase in ubiquitinated forms of $\alpha$-actin. Ubiquitination is an essential step for the degradation of proteins targeted to be degraded through the Ubpathway. The up-regulation of the Ub-pathway caused by DEXA treatment and the associated decrease in myofibrillar proteins lead to increased ubiquitination of $\alpha$-actin, the final step for degradation of proteins by the Ub-pathway. Altogether, our results clearly show that DEXA activates the Ub-pathway in heart.

Although we made an attempt, by using protease inhibitors, to inhibit endogenous deubiquitinases, the enzymes which cleave polyubiquitin chains, our data might have been affected by any remaining deubiquitinase activity. In any case, the interpretation of our results should not have been affected since any remaining deubiquitinase activity does not differ between groups. Furthermore, any incomplete inhibition of deubiquitinases would just lead to an underestimation of the ubiquitination of proteins by DEXA treatment.

In DEXA treated rats, we found a 7.8\% reduction in heart weight compared to controls, whereas body weight was decreased by as much as $26 \%$ compared 
to the control group. In addition, in the same experimental model we previously found that DEXA causes a $24 \%$ reduction of the gastrocnemius muscle weight. ${ }^{26}$ The fact that the heart weight expressed as a percentage of total body weight was higher in DEXA treated animals compared to controls shows that this treatment results in a relatively higher cardiac mass compared to control animals. We have previously shown that in skeletal muscle of the same experimental model, DEXA induces greater increases in Ub-protein conjugates (3-fold increase) and mRNAs encoding Ub, E2-14kDa, and proteasomes subunits (12-, 6-, and 4-fold increase, respectively) compared to heart. ${ }^{26,27}$ This could indicate a more robust activation of the Ub-pathway and subsequently a higher rate of proteolysis in skeletal muscle compared to heart muscle. The milder effect of DEXA on heart muscle weight compared to skeletal muscle could be the result of a milder activation of the Ub-pathway and proteolysis in combination with positive effects on heart tissue such as increased cell survival. Indeed, glucocorticoids have been demonstrated to have anti-apoptotic effects in heart muscle tissue as well as in cultured cardiomyocytes. ${ }^{38-40}$ Altogether, the above findings suggest that the heart is relatively resistant to the catabolic actions of DEXA compared to skeletal muscle.

Co-administration of IGF-1 completely prevented DEXA-induced growth arrest of the heart. In rats treated with DEXA plus IGF-1, heart weight had a tendency to be even higher than in control animals. As DEXA plus IGF-1 only partially preserved body weight, this possibly indicates that the treatment potentially leads to an increased percentage of heart weight per body weight compared to the control group. IGF-1 is an anabolic peptide and promotes growth not only by increasing proliferation, cell survival, and protein synthesis but also by decreasing protein breakdown. ${ }^{25,41-43}$ In models of catabolism, such as fasting, ${ }^{44}$ burn injury, ${ }^{45}$ and glucocorticoid treatment, ${ }^{26}$ IGF-1 treatment decreases mRNA abundance of components of the Ub-pathway and therefore the Ub-proteasome pathway is considered as a mediator of the anti-proteolytic actions of IGF-1. Furthermore, IGF-1 is known to down-regulate the expression of the ubiquitin ligases atrogin-1 and MuRF-1, both im- portant in skeletal muscle for the targeting of proteins to be degraded through the Ub-pathway. ${ }^{22,24,46}$ This is accomplished by the inhibition of the transcription factor FOXO, a major stimulant of atrogin-1 and MuRF-1. $24,47,48$

We demonstrated that IGF-1 regulates not only mRNAs encoding components of the Ub-pathway but also decreases the levels of Ub-conjugated proteins, the $20 \mathrm{~S}$ proteasome protein and, most importantly, the ubiquitinated forms of $\alpha$-actin. In addition to its anti-proteolytic actions, IGF-1 has also been reported to increase the synthesis of cardiac myosin heavy chain and actin in rats ${ }^{32}$ and therefore we cannot exclude that the observed increases in actin are only due to decreased proteolysis..$^{32}$ It is noteworthy that the effect of IGF-1 administration was more pronounced in preserving heart weight than body weight. In normal rats receiving IGF-1 increased protein synthesis, cellular hypertrophy, and survival leading to cardiac hypertrophy and improved cardiac performance has been observed..$^{30}$ In addition, IGF-1 exerts cardioprotective effects and improves cardiac function in different animal models with cardiac infarction and heart failure. ${ }^{49-55}$ Since in this setting the Ub-pathway has been implicated, ${ }^{56-59}$ one could hypothesize that the cardioprotective effects of IGF-1 detected in those conditions are mediated not only through increased cell survival and protein synthesis but also through regulation of the Ub-pathway.

We conclude that high-dose DEXA treatment in rats leads to an arrest of heart growth with a concurrent activation of the ubiquitin proteolytic pathway and subsequent degradation of myofibrillar proteins. Co-treatment with IGF-1 prevented the DEXAinduced suppression of heart growth and also the activation of components of the Ub-pathway as well as the ubiquitination of actin. Our findings suggest an additional mechanism for IGF-1 in cardioprotective action, namely through regulation of the ubiquitin pathway in the heart.

\section{DECLARATION OF INTEREST}

We declare that there is no conflict of interest that could be perceived as prejudicing the impartiality of the research reported. 


\section{FUNDING}

This research was supported by the Swedish Research Council (LS; project K2010-54X -15073-07-3), Stockholm City Council, Stiftelsen Frimurare Barnhuset i Stockholm, Sällskapet Barnavård, Stiftelsen Samariten, and HKH Kronprinsessan Lovisas förening för Barnasjukvård.

\section{REFERENCES}

1. Goldberg AL, 1969 Protein turnover in skeletal muscle. II. Effects of denervation and cortisone on protein catabolism in skeletal muscle. J Biol Chem 244: 32233229.

2. Dardevet D, Sornet C, Taillandier D, Savary I, Attaix D, Grizard J, 1995 Sensitivity and protein turnover response to glucocorticoids are different in skeletal muscle from adult and old rats. Lack of regulation of the ubiquitin-proteasome proteolytic pathway in aging. J Clin Invest 96: 2113-2119.

3. Auclair D, Garrel DR, Chaouki Zerouala A, Ferland LH, 1997 Activation of the ubiquitin pathway in rat skeletal muscle by catabolic doses of glucocorticoids. Am J Physiol 272: C1007-1016.

4. Menconi M, Fareed M, O’Neal P, Poylin V, Wei W, Hasselgren PO, 2007 Role of glucocorticoids in the molecular regulation of muscle wasting. Crit Care Med 35: S602-608.

5. Tisdale MJ, 2007 Is there a common mechanism linking muscle wasting in various disease types? Curr Opin Support Palliat Care 1: 287-292.

6. Eldridge AG, O'Brien T, Therapeutic strategies within the ubiquitin proteasome system. Cell Death Differ 17: 4-13.

7. Mitch WE, Goldberg AL 1996 Mechanisms of muscle wasting. The role of the ubiquitin-proteasome pathway. N Engl J Med 335: 1897-1905

8. Liu Z, Miers WR, Wei L, Barrett EJ, 2000 The ubiquitinproteasome proteolytic pathway in heart vs. skeletal muscle: effects of acute diabetes. Biochem Biophys Res Commun 276: 1255-1260.

9. Bulteau AL, Szweda LI, Friguet B, 2002 Age-dependent declines in proteasome activity in the heart. Arch Biochem Biophys 397: 298-304.

10. Fielitz J, van Rooij E, Spencer JA, et al, 2007 Loss of muscle-specific RING-finger 3 predisposes the heart to cardiac rupture after myocardial infarction. Proc Natl Acad Sci U S A 104: 4377-4382.

11. Willis MS, Schisler JC, Li L, et al, 2009 Cardiac muscle ring finger-1 increases susceptibility to heart failure in vivo. Circ Res 105: 80-88.

12. Fang CX, Dong F, Thomas DP, Ma H, He L, Ren J, 2008 Hypertrophic cardiomyopathy in high-fat diet-induced obesity: role of suppression of forkhead transcription factor and atrophy gene transcription. Am J Physiol Heart Circ Physiol 295: H1206-H1215.

13. Weekes J, Morrison K, Mullen A, Wait R, Barton P, Dunn MJ, 2003 Hyperubiquitination of proteins in dilated cardiomyopathy. Proteomics 3: 208-216.

14. Okada K, Wangpoengtrakul C, Osawa T, Toyokuni S, Tanaka K, Uchida K, 1999 4-Hydroxy-2-nonenalmediated impairment of intracellular proteolysis during oxidative stress. Identification of proteasomes as target molecules. J Biol Chem 274: 23787-23793.

15. Bulteau AL, Lundberg KC, Humphries KM, et al, 2001 Oxidative modification and inactivation of the proteasome during coronary occlusion/reperfusion. J Biol Chem 276: 30057-30063.

16. Sicard RE, Werner JC, 1992 Dexamethasone induces a transient relative cardiomegaly in neonatal rats. Pediatr Res 31: 359-363.

17. Griffin EE, Wildenthal K, 1978 Regulation of cardiac protein balance by hydrocortisone: interaction with insulin. Am J Physiol 234: E306-313.

18. Rannels SR, Rannels DE, Pegg AE, Jefferson LS, 1978 Glucocorticoid effects on peptide-chain initiation in skeletal muscle and heart. Am J Physiol 235: E134-139

19. Kelly FJ, Goldspink DF, 1982 The differing responses of four muscle types to dexamethasone treatment in the rat. Biochem J 208: 147-151.

20. Clark AF, DeMartino GN, Wildenthal K, 1986 Effects of glucocorticoid treatment on cardiac protein synthesis and degradation. Am J Physiol 250: C821-827.

21. Frost RA, Nystrom GJ, Jefferson LS, Lang CH, 2007 Hormone, cytokine, and nutritional regulation of sepsisinduced increases in atrogin-1 and MuRF1 in skeletal muscle. Am J Physiol Endocrinol Metab 292: E501-512.

22. Lang CH, Huber D, Frost RA 2007 Burn-induced increase in atrogin-1 and MuRF-1 in skeletal muscle is glucocorticoid independent but downregulated by IGF-I. Am J Physiol Regul Integr Comp Physiol 292: R328-336.

23. Clemmons DR, 2009 Role of IGF-I in skeletal muscle mass maintenance. Trends Endocrinol Metab 20: 349356.

24. Schakman O, Gilson H, Thissen JP 2008 Mechanisms of glucocorticoid-induced myopathy. J Endocrinol 197: $1-10$.

25. Fang CH, Li BG, Wang JJ, Fischer JE, Hasselgren PO, 1997 Insulin-like growth factor 1 stimulates protein synthesis and inhibits protein breakdown in muscle from burned rats. JPEN J Parenter Enteral Nutr 21: 245-251.

26. Chrysis D, Underwood LE, 1999 Regulation of components of the ubiquitin system by insulin-like growth factor I and growth hormone in skeletal muscle of rats made catabolic with dexamethasone. Endocrinology 140: 5635-5641.

27. Chrysis D, Zhang J, Underwood LE 2002 Divergent regulation of proteasomes by insulin-like growth factor I and growth hormone in skeletal muscle of rats made 
catabolic with dexamethasone. Growth Horm IGF Res 12: 434-441.

28. Schakman O, Kalista S, Bertrand L, et al, 2008 Role of Akt/GSK-3beta/beta-catenin transduction pathway in the muscle anti-atrophy action of insulin-like growth factor-I in glucocorticoid-treated rats. Endocrinology 149: 3900-3908.

29. Cittadini A, Ishiguro Y, Stromer H, et al, 1998 Insulinlike growth factor-1 but not growth hormone augments mammalian myocardial contractility by sensitizing the myofilament to $\mathrm{Ca} 2+$ through a wortmannin-sensitive pathway: studies in rat and ferret isolated muscles. Circ Res 83: 50-59.

30. Reiss K, Cheng W, Ferber A, et al, 1996 Overexpression of insulin-like growth factor-1 in the heart is coupled with myocyte proliferation in transgenic mice. Proc Natl Acad Sci U S A 93: 8630-8635.

31. Cittadini A, Stromer H, Katz SE, et al, 1996 Differential cardiac effects of growth hormone and insulin-like growth factor- 1 in the rat. A combined in vivo and in vitro evaluation. Circulation 93: 800-809.

32. Young LH, Renfu Y, Hu X, et al, 1999 Insulin-like growth factor I stimulates cardiac myosin heavy chain and actin synthesis in the awake rat. Am J Physiol 276: E143-150.

33. Komamura K, Shirotani-Ikejima H, Tatsumi R, et al, 2003 Differential gene expression in the rat skeletal and heart muscle in glucocorticoid-induced myopathy: analysis by microarray. Cardiovasc Drugs Ther 17: 303-310.

34. Kim HT, Kim KP, Lledias F, et al, 2007 Certain pairs of ubiquitin-conjugating enzymes (E2s) and ubiquitinprotein ligases (E3s) synthesize nondegradable forked ubiquitin chains containing all possible isopeptide linkages. J Biol Chem 282: 17375-17386.

35. Kedar V, McDonough H, Arya R, Li HH, Rockman HA, Patterson C, 2004 Muscle-specific RING finger 1 is a bona fide ubiquitin ligase that degrades cardiac troponin I. Proc Natl Acad Sci U S A 101: 18135-18140.

36. Solomon V, Goldberg AL 1996 Importance of the ATP-ubiquitin-proteasome pathway in the degradation of soluble and myofibrillar proteins in rabbit muscle extracts. J Biol Chem 271: 26690-26697.

37. Loo JA, Berhane B, Kaddis CS, et al, 2005 Electrospray ionization mass spectrometry and ion mobility analysis of the 20S proteasome complex. J Am Soc Mass Spectrom 16: 998-1008.

38. Pearl JM, Nelson DP, Schwartz SM, et al, 2002 Glucocorticoids reduce ischemia-reperfusion-induced myocardial apoptosis in immature hearts. Ann Thorac Surg 74: 830-837.

39. Chen QM, Alexander D, Sun H, et al, 2005 Corticosteroids inhibit cell death induced by doxorubicin in cardiomyocytes: induction of antiapoptosis, antioxidant, and detoxification genes. Mol Pharmacol 67: 1861-1873.

40. Reeve JL, Szegezdi E, Logue SE, et al, 2007 Distinct mechanisms of cardiomyocyte apoptosis induced by doxorubicin and hypoxia converge on mitochondria and are inhibited by Bcl-xL. J Cell Mol Med 11: 509-520.

41. Oehri M, Ninnis R, Girard J, Frey FJ, Keller U, 1996 Effects of growth hormone and IGF-I on glucocorticoidinduced protein catabolism in humans. Am J Physiol 270: E552-558.

42. Jacob R, Barrett E, Plewe G, Fagin KD, Sherwin RS, 1989 Acute effects of insulin-like growth factor I on glucose and amino acid metabolism in the awake fasted rat. Comparison with insulin. J Clin Invest 83: 17171723.

43. Tomas FM, Knowles SE, Owens PC, et al, 1992 Insulinlike growth factor-I (IGF-I) and especially IGF-I variants are anabolic in dexamethasone-treated rats. Biochem $\mathrm{J}$ 282(Pt 1): 91-97.

44. Jagoe RT, Lecker SH, Gomes M, Goldberg AL, 2002 Patterns of gene expression in atrophying skeletal muscles: response to food deprivation. Faseb J 16: 1697-1712.

45. Fang CH, Li BG, Tiao G, Wang JJ, Fischer JE, Hasselgren PO, 1998 The molecular regulation of protein breakdown following burn injury is different in fast- and slow-twitch skeletal muscle. Int J Mol Med 1: 163-169.

46. Sacheck JM, Ohtsuka A, McLary SC, Goldberg AL, 2004 IGF-I stimulates muscle growth by suppressing protein breakdown and expression of atrophy-related ubiquitin ligases, atrogin-1 and MuRF1. Am J Physiol Endocrinol Metab 287: E591-601.

47. Sandri M, Sandri C, Gilbert A, et al, 2004 Foxo transcription factors induce the atrophy-related ubiquitin ligase atrogin-1 and cause skeletal muscle atrophy. Cell 117: 399-412.

48. Stitt TN, Drujan D, Clarke BA, et al, 2004 The IGF$1 / \mathrm{PI} 3 \mathrm{~K} / \mathrm{Akt}$ pathway prevents expression of muscle atrophy-induced ubiquitin ligases by inhibiting FOXO transcription factors. Mol Cell 14: 395-403.

49. Otani H, Yamamura T, Nakao Y, et al, 2000 Insulin-like growth factor-I improves recovery of cardiac performance during reperfusion in isolated rat heart by a wortmannin-sensitive mechanism. J Cardiovasc Pharmacol 35: 275-281.

50. Friehs I, Stamm C, Cao-Danh H, McGowan FX, del Nido PJ, 2001 Insulin-like growth factor-1 improves postischemic recovery in hypertrophied hearts. Ann Thorac Surg 72: 1650-1656.

51. Tivesten A, Caidahl K, Kujacic V, et al, 2001 Similar cardiovascular effects of growth hormone and insulinlike growth factor-I in rats after experimental myocardial infarction. Growth Horm IGF Res 11: 187-195.

52. Yamashita K, Kajstura J, Discher DJ, et al, 2001 Reperfusion-activated Akt kinase prevents apoptosis in transgenic mouse hearts overexpressing insulin-like growth factor-1. Circ Res 88: 609-614.

53. Matthews KG, Devlin GP, Stuart SP, et al, 2005 Intrapericardial IGF-I improves cardiac function in an ovine model of chronic heart failure. Heart Lung Circ 
14: 98-103.

54. Saetrum Opgaard O, Wang PH 2005 IGF-I is a matter of heart. Growth Horm IGF Res 15: 89-94.

55. Le Corvoisier P, Hittinger L, Chanson P, Montagne O, Macquin-Mavier I, Maison P, 2007 Cardiac effects of growth hormone treatment in chronic heart failure: A meta-analysis. J Clin Endocrinol Metab 92: 180-185.

56. Gomes AV, Zong C, Ping P, 2006 Protein degradation by the $26 \mathrm{~S}$ proteasome system in the normal and stressed myocardium. Antioxid Redox Signal 8: 1677-1691.

57. Willis MS, Patterson C, 2006 Into the heart: the emerg- ing role of the ubiquitin-proteasome system. J Mol Cell Cardiol 41: 567-579.

58. Majetschak M, Patel MB, Sorell LT, Liotta C, Li S, Pham SM, 2008 Cardiac proteasome dysfunction during cold ischemic storage and reperfusion in a murine heart transplantation model. Biochem Biophys Res Commun 365: 882-888.

59. Mearini G, Schlossarek S, Willis MS, Carrier L, 2008 The ubiquitin-proteasome system in cardiac dysfunction. Biochim Biophys Acta 1782: 749-763. 